\title{
Perancangan Aplikasi Penagihan Pelanggan Tv Kabel Berbasis Android
}

\author{
Rendra Soekarta ${ }^{1}$, Irman Amri ${ }^{2}$, Muhamad Luqman Hidayatulah ${ }^{3}$ \\ Jurusan Teknik Informatika, Fakultas Teknik Universitas Muhammadiyah Sorong \\ Email: *1 rsoekarta@um-sorong.ac.id, *2 irmanamri_srg@yahoo.com, \\ *33uhamadluqmanha@gmail.com
}

\begin{abstract}
Abstrak
Berdasarkan hasil analisis yang telah dilakukan peneliti, tagihan iuran tvkabel di Tv Kabel Merpati selama inimasih manual menggunakan buku yang cukup tebal baik dalam penagihan maupun administrasi lainnya. Peneliti ini bertujuan untuk menganalisis dan merancang suatu aplikasi yang dapat memudahkan unit penagihan dalam proses penagihan dan tidak lagi membawa buku tebal. Aplikasi ini deprogram denggan menggunakan bahasa angulerJs dan ionic sebagai frameworknya dan juga nysql sebagai databasenya. Diharapkan Aplikasi ini dapat diimplementasikan dan memenuhi kebutuhan dari Unit Penagihan Tv Kabel Merpati Kabupaten sorong dalam melakukan pengelolahan data tagihan secara efektif dan efesien cukup menggunakan smartphone dan tanpa manual menggunakan buku tebal lagi.
\end{abstract}

Kata kunci Android, Ionic, AngulerJs, Penagihan, Pelanggan, Mysql, Equivalence, Boundary

\section{PENDAHULUAN}

$\mathrm{P}$ erusahaan Tv kabel merpati memiliki pelanggan yang mencakup Kabupaten sorong dan sekitarnya. Dengan begitu banyaknya pelanggan, Tv kabel merpati harus memberikan pelayanan yang optimal, terutama pelayanan untuk tagihan. Proses pelayanan kegiatan administrasi pembayaran dimulai dari pencatatan pembayaran, pemberian bukti pembayaran dan pencarian data pembayaran di Tv kabel merpati masih menggunakan sistem manual yaitu menggunakan buku yang tebal. Dokumentasi pembayaran hanya berupa penulisan di buku besar. Sehingga segala sesuatu yang menyangkut tentang data tersebut mempunyai kegunaan atau nilai tertentu yang diperlukan tidak dapat mudah ditemukan.

Unit Penagihan adalah salah satu divisi dari Tv Kabel Merpati Kabupaten Sorong yang bergerak dibidang penagihan iuran bulanan. Unit Penagihan sampai saat ini dalam melakukan pengolahan data seperti mengelola data tagihan masih dilakukan secara manual.

Sistem informasi yang masih manual banyak sekali terdapat kekurangan, seperti memerlukan waktu yang cukup lama dalam memproses data, ketidakakuratan dari proses serta keterlambatan dalam memberikan informasi maupun laporan. Tv kabel merpati dirasa perlu untuk merubah metode 
pengelolaan administrasi tagihan yang saat ini sedang berjalan, yaitu metode manual menjadi metode administrasi pembayaran yang terdigitalisasi.

Sistem informasi tagihan di Perusahaan Tv Kabel Merpati akan dibangun dengan memanfaatkan PHP sebagai pembuatan sistemnya dan MySQL sebagai pengelola basis datanya. PHP menyediakan berbagai kemudahan dan dukungan dalam pengembangan aplikasi berbasis android spartphone, MySql merupakan database yang gratis dan telah mendukung teknologi database terbaru.

Berdasarkan masalah tersebut di atas maka judul yang diambil dalam skripsi ini adalah "Aplikasi Penagihan Pelanggan Tv Kabel Berbasis Android". Diharapkan sistem informasi ini dapat membantu Perusahaan Tv Kabel Merpati dalam melakukan administrasi tagihan yang lebih efektif dan efisien.

\section{METODE PENELITIAN}

2.1 Bagan Alir Penelitian

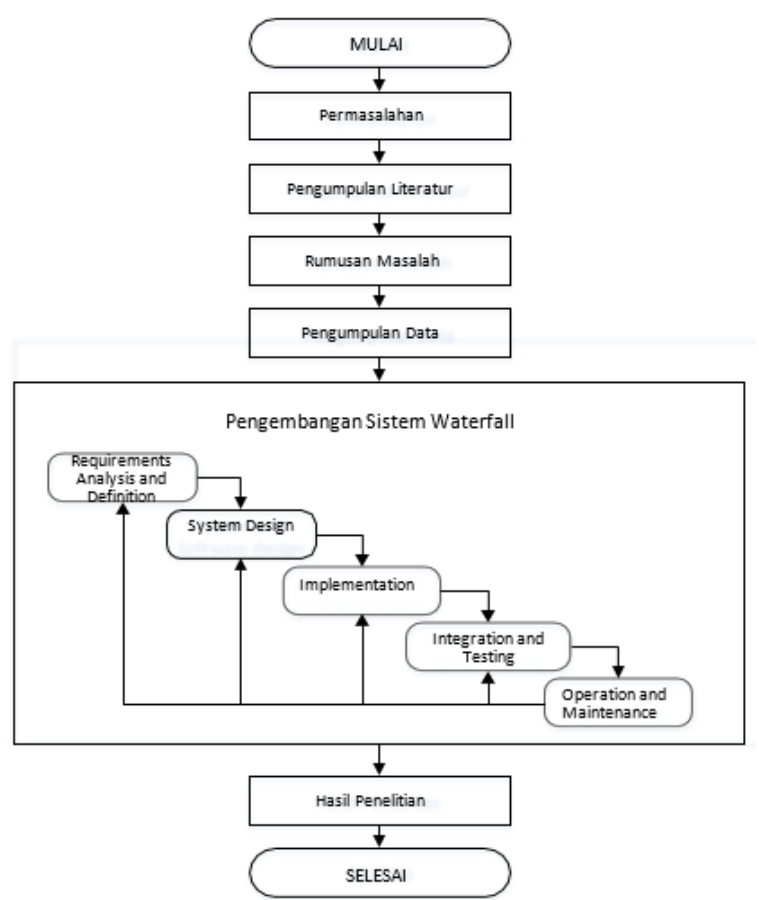

Gambar 2.1 Bagan Alir Penelitian

Berikut adalah penjelasan dari tahapan-tahapan tersebut:

1.Requirement Analysis and Definition

Merupakan tahapan penetapan fitur, kendala dan tujuan sistem melalui konsultasi dengan pengguna sistem. Semua hal tersebut akan ditetapkan secara rinci dan berfungsi sebagai spesifikasi sistem.

\section{System and Software Design}

Dalam tahapan ini akan dibentuk suatu arsitektur sistem berdasarkan persyaratan yang telah ditetapkan. Dan juga mengidentifikasi dan menggambarkan abstraksi dasar sistem perangkat lunak dan hubunganhubungannya.

3.Implementation and Unit Testing 
Dalam tahapan ini, hasil dari desain perangkat lunak akan direalisasikan sebagai satu set program atau unit program. Setiap unit akan diuji apakah sudah memenuhi spesifikasinya.

\section{Integration and System Testing}

Dalam tahapan ini, setiap unit program akan diintegrasikan satu sama lain dan diujisebagai satu sistem yang utuh untuk memastikan sistem sudah memenuhi persyaratan yang ada. Setelah itu sistem akan dikirim ke pengguna sistem.

5.Operation and Maintenance

Dalam tahapan ini, sistem diinstal dan mulai digunakan. Selain itu juga memperbaiki error yang tidak ditemukan pada tahap pembuatan. Dalam tahap ini juga dilakukan pengembangan sistem seperti penambahan fitur dan fungsi baru." (Rosmiati, $2015: 3$ ).

\subsection{Flowchart}

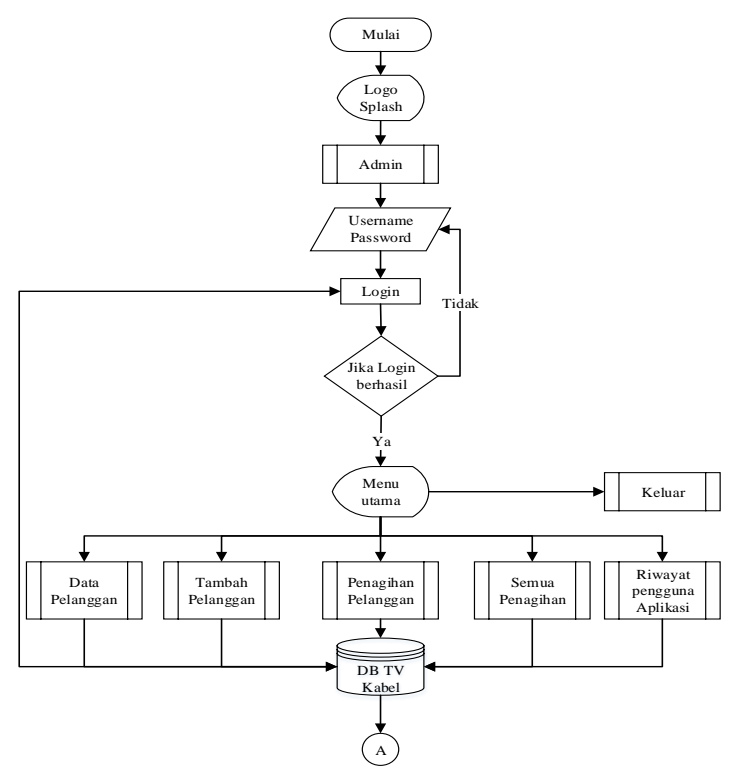

Gambar 2.2 Flowchart

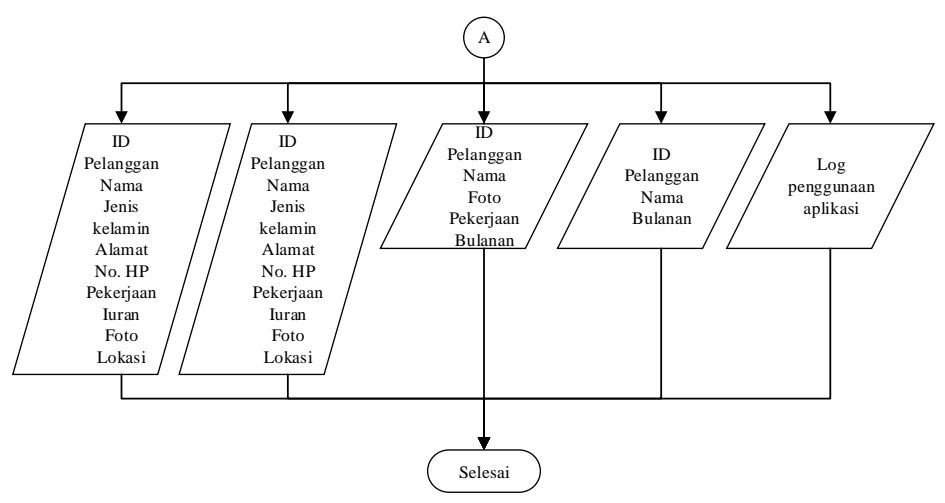

Gambar 2.3 Flowchart (lanjutan) 


\section{HASIL DAN PEMBAHASAN}

3.1 Usecase Diagram

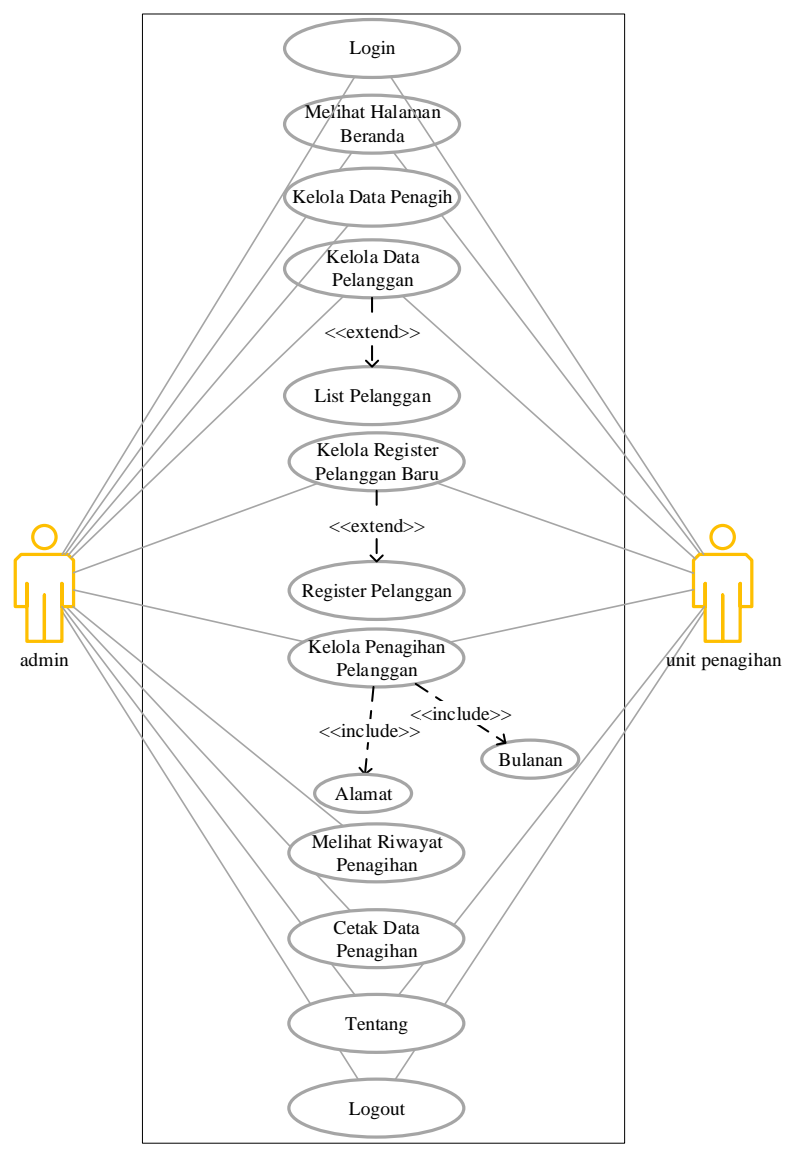

Gambar 3.1 Usecase Giagram

Pada gambar 3.1 menjelaskan terdapat dua actor yaitu admin dan unit penagihan. Admin memiliki hak akses untuk mengelola tagihan yang didalamnya terdapat menu data pelanggan (ubah/hapus/search), menu tambah pelanggan (register pelanggan), menu penagihan pelanggan, menu riwayat penagihan unit penagihan, menu manage akun (untuk menambah akun admin dana kun penagih) menu cetak data penagihan, menu tentang dan menu logout. Sedangkan unit penagihan terdapat menu data pelanggan (ubah/hapus/search), menu tambah pelanggan (register pelanggan), menu penagihan pelanggan, menu tentang dan menu logout.

\subsection{Class Diagram}




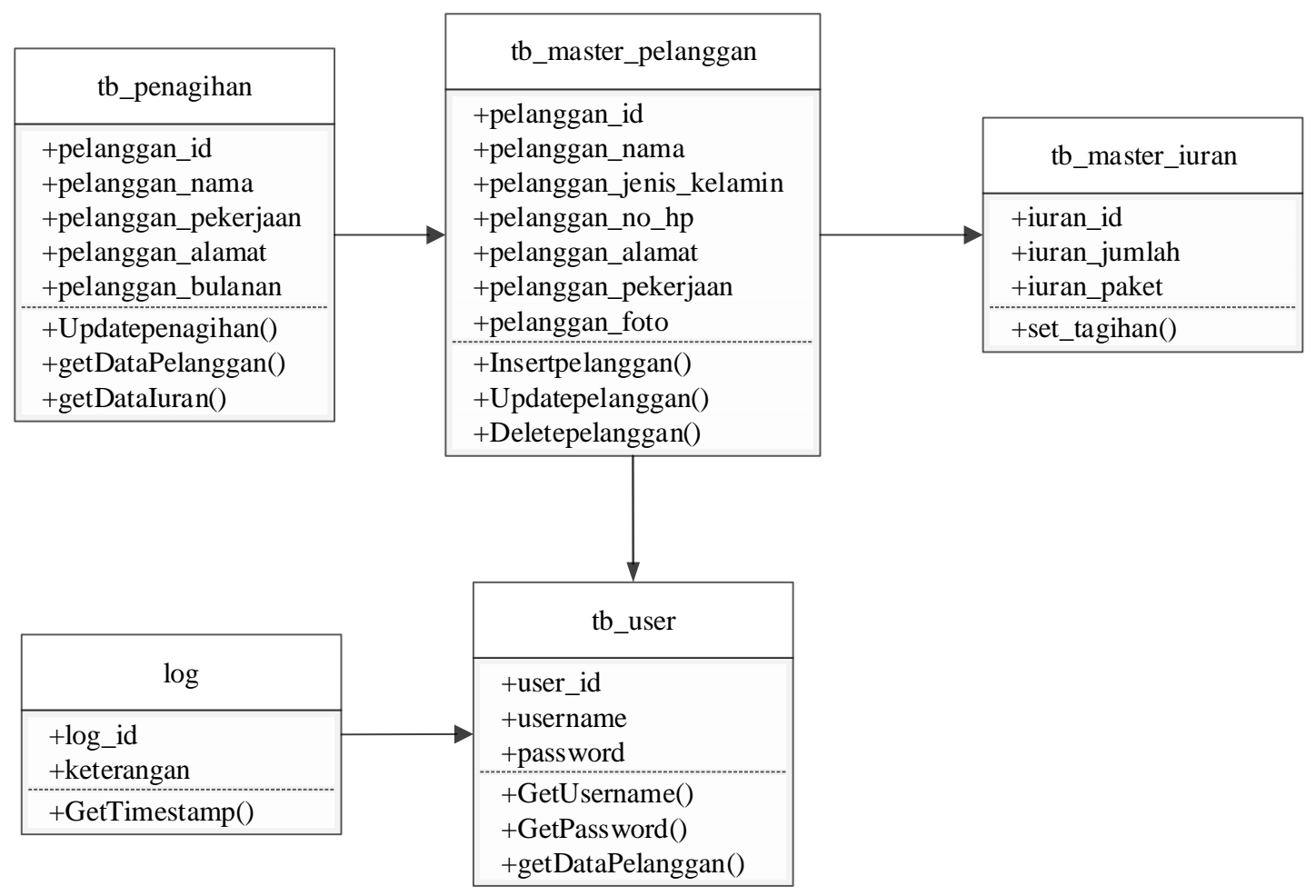

Gambar 3.2 Class Diagram

Berikut adalah penjelasan dari masing - masing kelas atau entity Pada gambar 3.2:

1. tb_master_pelanggan: terdiri dari informasi pelanggan seperti id pelanggan, nama pelanggan, jenis kelamin pelanggan, no hp pelanggan, alamat pelanggan, pekerjaan pelanggan, foto rumah pelanggan.

2. tb_penagihan: terdiri dari id pelanggan, bulanan pembayaran.

3. tb_master_iuran: terdiri dari jumlah dan paket iuran pelanggan

4. tb_user: terdiri dari admin dan unit penagihan.

5. log: menampung aktifitas penggunaan user dalam menggunakan aplikasi. 


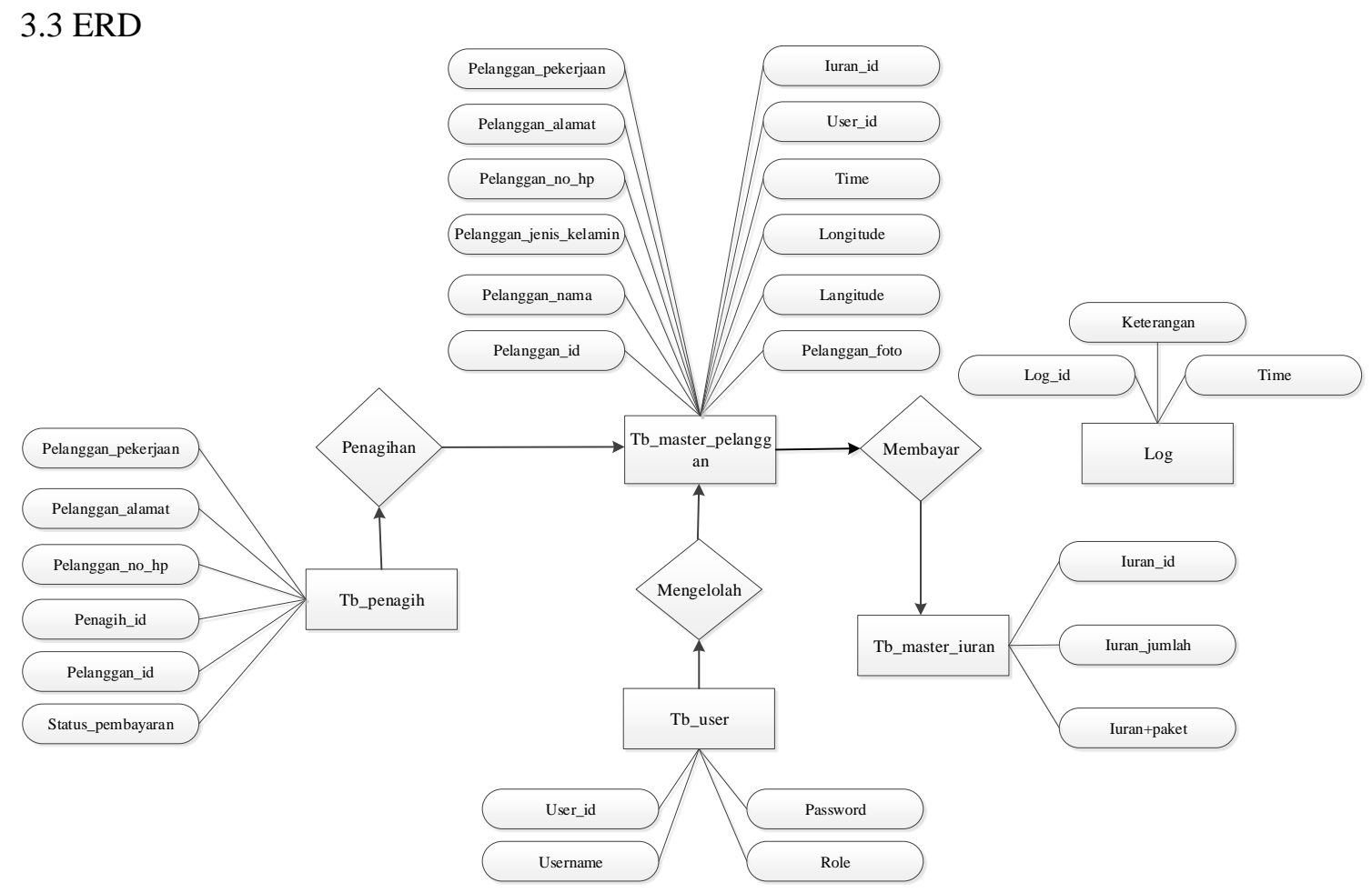

Gambar 3.3 Entity Relationship Diagram

Pada gambar 3.3 adalah erd dalam aplikasi penagihan pelanggan tv kabel berbasis android.

\subsection{Desain Basis Data}

Desain basis data dibuat menggunakan diagram erd dan digunakan untuk menyimpan setiap data yang di inputkan pada system pakar. Setiap table memiliki salah satu data yang digunakan sebagai primery key. Gambar erd dapat dilihat pada gambar 3.3

a. Conceptual Data Model (CDM)

Model yang dibuat berdasarkan anggapan bahwa dunia nyata terdiri dari koleksi obyek-obyek dasar yang dinamakan entitas (entity) serta hubungan (relationship) antara entitas-entitas itu. Biasanya direpresentasikan dalam bentuk Entity Relationship Diagram.

Dibawah ini merupakan Conceptual Data Model yang relasi antara lain master pelanggan dengan penagihan yaitu One to One, user dengan master pelanggan yaitu One to Many dan master pelanggan dengan master iuran yaitu One to One. 


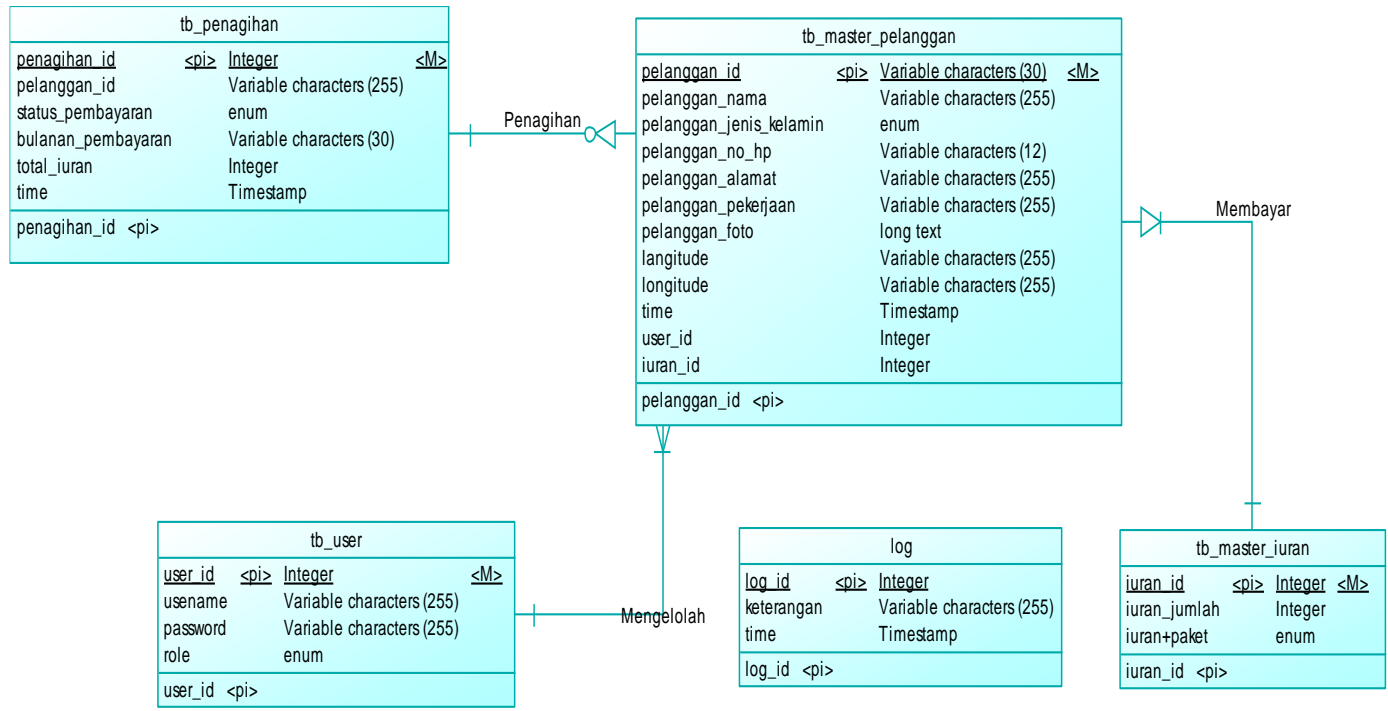

Gambar 3.4 Gambar Conceptual Data Model

\section{b. Physical Data Model (PDM)}

Merupakan model yang menggunakan sejumlah tabel untuk menggambarkan data serta hubungan antara data-data tersebut. Setiap tabel mempunyai sejumlah kolom di mana setiap kolom memiliki nama yang unik.

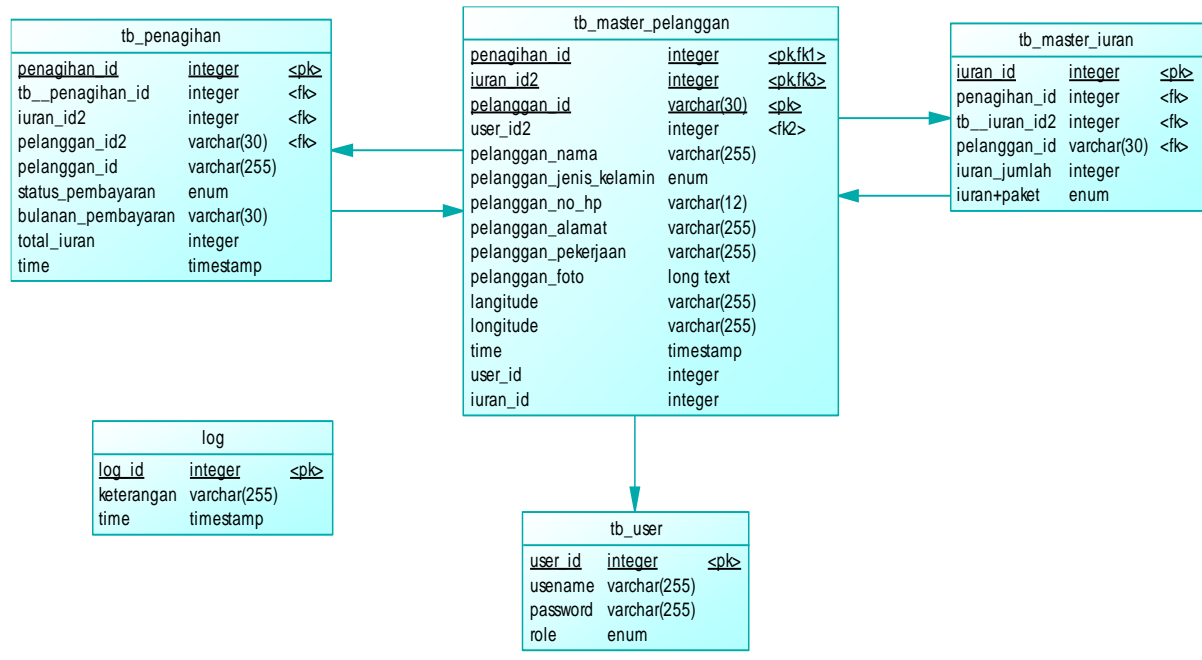

Gambar 3.5 Gambar Physical Data Model

\subsection{Implementasi}

Dibawah ini merupakan Implementasi interface tampilan manu yang ada pada Aplikasi Penagihan Tv kabel merpati berbasis android. 
a. Tampilan Halaman Utama

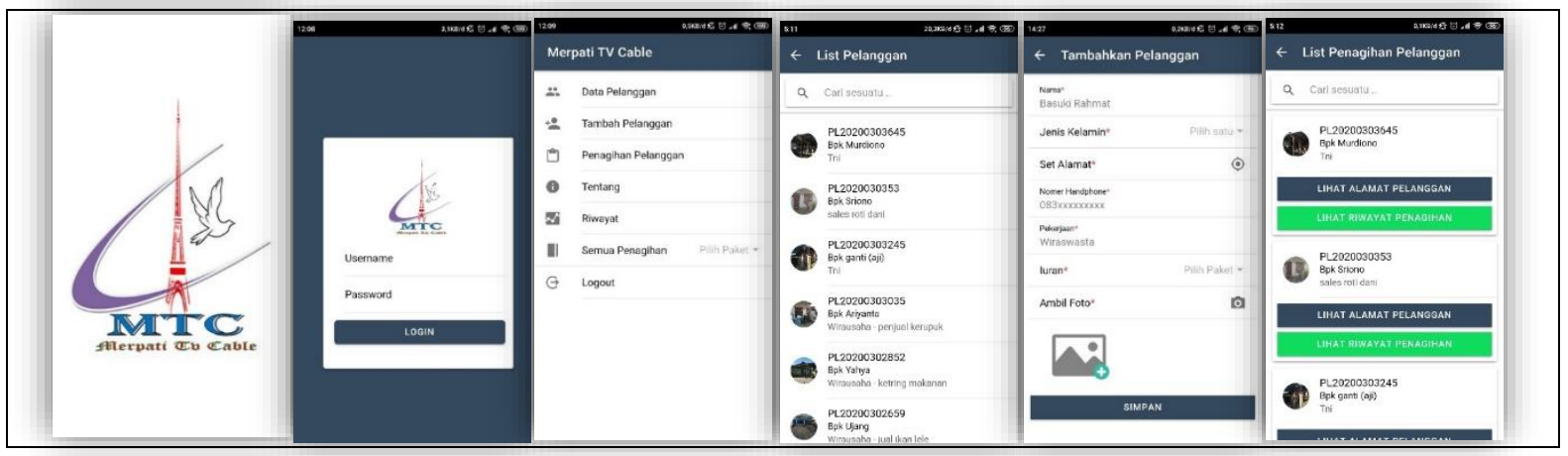

Gambar 3.6 Tampilan Login, Home Menu, List Pelanggan, Daftar Pelanggan, Penagihan Pelanggan

b. Tampilan Halaman Info

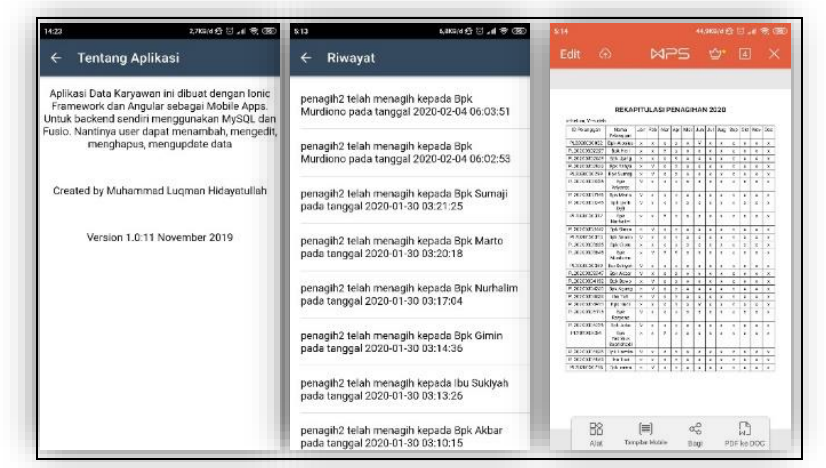

Gambar 3.7 Tampilan Tentang, Log, Export laporan Pdf

\section{KESIMPULAN}

Berdasarkan hasil penelitian yang telah dilakukan dapat disumpulkan :

1. Aplikasi ini dapat diimplementasikan dan memenuhi kebutuhan dari Unit Penagihan Tv Kabel Merpati Kabupaten sorong dalam melakukan pengelolahan data tagihan secara efektif dan efesien cukup menggunakan smartphone dan tanpa manual menggunakan buku tebal lagi.

2. Aplikasi yang dibuat dapat mempercepat proses penagihan pelanggan.

3. Data setiap pelanggan dapat terarsip rapi dalam database.

4. Sistem rekapitulasi pelanggan memudahkan pengarsipan data tagihan setiap tahun.

\section{SARAN}

Penelitian yang telah dilakukan masih terdapat kekurangan dan masih dapat dikaji lebih lanjut. Oleh karena itu peneliti memberikan saran - saran terkait pengembangan penelitian ini yaitu :

1. Menggunakan database yang lebih cepat selain database mysql

2. Membuat directions yang langsung membuka aplikasi google maps 


\section{UCAPAN TERIMA KASIH}

Alhamdulillah, Puji syukur kehadirat Allah Subhanahu Wa Ta'ala yang telah melimpahkan Rahmat-Nya sehingga Skripsi dengan judul "Perancangan Aplikasi Penagihan Pelanggan Tv Kabel Berbasis Android" dapat terselesaikan dengan baik. Ibu, Bapak, semua keluarga besarku' dan Teman teman yang selalu mensuport. Terima kasih untuk do'a, dukungan, kasih sayang, dan segalanya.

\section{DAFTAR PUSTAKA}

[1] Adelheid A., dan Aqilha S., 2012. Manual Book of Android. Jogjakarta: Litera Media Creativa. ISBN: 978602-18836-4-8

[2] Agiato, B., Somantri, M., \& Sinuraya, E. W. (2018). Perancangan Aplikasi Informasi Tagihan Listrik, Pdam, Dan Telepon Berbasis Android Pada Wisma Parikesit Tegalrejo Kota Salatiga. Transient, 7(2), 671-677.

[3] Dharmawan, E. A. (2018). Implementasi Sistem Konfirmasi Pembayaran Pinjaman Pada Koperasi Simpan Pinjam Berbasis Android. Smartics Journal, 4(1), 23-27.

[4] Gata, Windu dan Gata, Grace. (2013). Sukses Membangun Aplikasi Penjualan dengan Java. Jakarta : Elex Media Komputindo.

[5] Irawan, I. (2018). Pengembangan Sistem Informasi Tagihan (Billing System) Pasien Rawat Inap Pada Rumah Sakit Umum Daerah Bangkinang Kampar. Riau Journal Of Computer Science, 4(2), $31-40$.

[6] Iswandy, E. (2016). Analisa Dan Perancangan Sistem Informasi Penagihan Purchasing Order Customer Studi Kasus Pada Cv. Vertical Cipta Relasi Padang Dengan Metode Centralized Data Processing. Jurnal Teknoif, 4(2).

[7] Latifah R., Ambo S. N., \& Yudha M. R. (2018). Sistem Informasi Penagihan Dana Kredit Tanpa Agunan Menggunakan Nä̈ve Bayes Di Bank Xyz. Konferensi Nasional Sistem Informasi.

[8] Mualindar, J., \& Mustofa, A. A. (2016). Perancangan Aplikasi Tagihan Spp Berbasis Android. Jurnal Sainstech Politeknik Indonusa Surakarta, 1(5).

[9] Mustaqbal, M. S., Firdaus, R. F., \& Rahmadi, H. (2016). Pengujian Aplikasi Menggunakan Black Box Testing Boundary Value Analysis (Studi Kasus: Aplikasi Prediksi Kelulusan SMNPTN). Jurnal Ilmiah Teknologi Informasi Terapan, 1(3).

[10] Najwaini, E., \& Pratomo, A. (2016). Aplikasi Pelayanan Pelanggan Berbasis Android Pada Pdam Kota Banjarmasin. POSITIF: Jurnal Sistem dan Teknologi Informasi, 2(1).

[11] Nidhira \& dondeti, 2. (2012). Black Box And White Box Testing Techniques A Literatur Review.Internasional Journal of Embedded System and Aplication ( IJESA ), Vol 2 (No.2),29-50. 
[12] Postdot Technology. 2017. Postman is the most complete API Development Environment. [Online]. San Francisco. Tersedia: https://www.getpostman.com/postman [30 Juli 2019].

[13] Ridlo, I. A. (2017). Panduan Pembuatan Flowchart.

[14] Soekarta, R. (2015). Rancang Bangun Sistem Informasi Akademik Berbasis Web (Studi Kasus Universitas Muhammadiyah Sorong). Insect (Informatics And Security): Jurnal Teknik Informatika, 1(1), 1-8.

[15] Suendri, S. (2019). Implementasi Diagram Uml (Unified Modelling Language) Pada Perancangan Sistem Informasi Remunerasi Dosen Dengan Database Oracle (Studi Kasus: Uin Sumatera Utara Medan). Algoritma: Jurnal Ilmu Komputer Dan Informatika, 2(2), 1.

[16] Sulihati \& Andriyani. (2016). Aplikasi Akademik Online Berbasis Mobile Android pada Universitas Tama Jagakarsa. Jurnal Sains dan Teknologi Utama. Volume XI, Nomor 1. 15-26. ISSN : 1978-001X.

[17] W.Kartika. (2014). Logika dan Algoritma.

[18] Wilken, J., \& Bradley, A. (2016). Ionic in action: Hybrid mobile apps with Ionic and AngularJS. Manning Publications. 